Author version: Earth Planet. Sci. Lett.: 284(3-4); 2009; 399-408

\title{
Early Oceanic Opening off Western India-Pakistan Margin: the Gop Basin Revisited
}

\author{
V. Yatheesh ${ }^{1,2, *}$, G.C. Bhattacharya ${ }^{1}$, J. Dyment $^{2}$ \\ ${ }^{1}$ National Institute of Oceanography, CSIR, Dona Paula, Goa - 403 004, India \\ ${ }^{2}$ Institut de Physique du Globe, CNRS UMR 7154, 75005 Paris, France
}

\begin{abstract}
The Deccan Traps, one of the best known examples of rapid flood basalt, are considered as marking of the inception of a mantle plume on the Indian continental lithosphere. Their emplacement may be associated with the continental break-up of India and the Seychelles block and later formation of a new spreading centre, the Carlsberg Ridge, while spreading progressively ceased in the Mascarene Basin. Whether rifting, continental break-up, and seafloor spreading predated or were the consequence of the Deccan Traps emplacement is still a matter of debate. This issue is further complicated by the presence of a continental sliver, the Laxmi Ridge, and large basins lying landward of the Laxmi Ridge, such as the Laxmi and Gop basins, where nature of the crust is still ambiguous. The present study attempts to decipher the tectonic setting and the imprints of plume-ridge interaction in the Gop Basin, where the crust has been interpreted as either volcanics-intruded thinned continental crust or oceanic crust formed by a now extinct spreading centre. Based on interpretation of an updated compilation of marine geophysical data, the present study supports the oceanic nature of the crust underlying the Gop Basin and proposes the Palitana Ridge as the extinct spreading centre in this region. The prominent but short sequence of fairly linear magnetic anomalies in the Gop Basin does not allow a unique identification; it can be reasonably explained either as A31r-A25r ( $69.3-56.4 \mathrm{Ma})$ or as A29r-A25r ( $\sim 64.8-56.4 \mathrm{Ma})$ sequence. The variations of the spreading rates assumed by both these models suggest that spreading in the Gop Basin significantly slowed around 65 $\mathrm{Ma}$, contemporaneous with the magmatic outburst of the Reunion plume on the adjacent western Indian mainland. Subsequently, the Gop Basin spreading centre was waning whereas a new spreading centre was developing further south, close to the (relatively) southward migrating plume. In this last stage, the Gop Basin spreading centre was associated with an abundant magmatism, probably supplied from the plume region.
\end{abstract}

Key words: Gop Basin, Palitana Ridge, magnetic lineations, extinct spreading centre, Reunion hotspot, Arabian Sea

* Corresponding author

E-mail: yatheesh@nio.org (V. Yatheesh)

Tel: +91 832 2450563; Fax: +91 8322450602

Yatheesh, V., Bhattacharya, G.C., Dyment, J., 2009. Early oceanic opening off Western India-Pakistan margin: the Gop Basin revisited. Earth and Planetary Science Letters 284(3-4), 399-408. 


\section{Introduction}

The conjugate Arabian and Eastern Somali basins (Northwestern Indian Ocean) have been formed by seafloor spreading along the Carlsberg Ridge since early Tertiary time; the Laxmi and Laccadive ridges mark the landward boundary of this oceanic crust in the Arabian Basin (McKenzie and Sclater, 1971; Norton and Sclater, 1979; Naini and Talwani, 1982; Schlich, 1982; Bhattacharya et al., 1992; Chaubey et al., 1993, 1998, 2002; Miles and Roest, 1993; Miles et al., 1998; Dyment, 1998; Royer et al., 2002). However, between the Laxmi Ridge and the India-Pakistan continental shelf is a wide region of deep offshore, whose genesis and evolution still remains to be confidently established. This region is important to understand the geodynamic evolution of the Arabian Sea region, as it includes the imprints of rifting of the India-Pakistan continental margin as well possible early phases of spreading. Furthermore, the geographical and temporal proximity of this region with the onset of the Deccan Traps, a huge continental flood basalt marking the inception of the Reunion hotspot mantle plume on the Indian lithosphere, also provides an opportunity to understand the interaction of such a plume with rifted continental margins and spreading ridges. The present study focuses on the Gop Basin, a $\sim 100 \mathrm{~km}$ wide part of this deep offshore region located immediately north of the northernmost, E-W trending segment of the Laxmi Ridge, between latitudes $19^{\circ} \mathrm{N}$ and $20^{\circ} \mathrm{N}$ (Fig. 1). The Gop Basin can be considered as a sub-basin of the Offshore Indus Basin (Miles et al., 1998; Bhattacharya and Chaubey, 2001), located between the landward boundary of the Laxmi Ridge and the India-Pakistan continental shelf.

Malod et al. (1997) were the first to delineate the Gop Basin in view of its basement structure and conspicuous magnetic lineations. They observed that the basement of the Gop Basin forms a sediment-filled E-W graben with a prominent central E-W horst. They referred the graben as the Gop Rift / Gop Graben, and the central horst as the Palitana Ridge / Palitana Horst. The various use of the terms 'rift' / 'graben' and 'horst' / 'ridge' in different papers related to this area appears to cause some confusion while discussing the genesis and nature of the crust underlying this region; in this paper we therefore refer to this region as the 'Gop Basin' and to the central basement high as the 'Palitana Ridge'. Opinions vary regarding the nature of the crust underlying the Gop Basin, from thinned continental crust intruded by volcanics to oceanic crust formed at a now-extinct spreading centre. 
The prominent high amplitude magnetic anomalies of the Gop Basin have drawn the attention of many researchers. Naini and Talwani (1982) recognized the existence of NWSE trending magnetic anomalies in this region, for which they considered a non-seafloor spreading origin since those anomalies did not match any part of the geomagnetic polarity time scale. Miles et al. (1998) interpreted those anomalies in terms of intrusives within a thinned continental crust. A seafloor-spreading origin was considered by several authors, with various interpretations. Masson (1984) viewed them as pre A28 lineations ( $63 \mathrm{Ma}$ according to the Geomagnetic Polarity Time Scale of Cande and Kent, 1995, consistently used in this study). Karasik et al. (1986, in Mercuriev et al., 1996) and Shreider (1998) interpreted them as the continuation of the Arabian Basin sequence up to A31 or A32 ( 69 and $\sim 73 \mathrm{Ma}$ ). Conversely, Malod et al. (1997) tentatively interpreted them as symmetrical A29r-A29n sequences ( 65.6 - $64 \mathrm{Ma})$, with a fossil spreading centre located north of the Palitana Ridge. Krishna et al. (2006) accepted their seafloor spreading origin without assigning them any ages. Very recently, both Collier et al. (2008) and Minshull et al. (2008) consider that the anomalies of the Gop Basin are due to basement topography of an oceanic crust and the edge effect at its margins but disagree on the identification of the anomalies: Collier et al. (2008) favour a three-polarity sequence (reversed-normal-reversed) formed during A31r - A32n, while Minshull et al. (2008) prefer a single reversed polarity block formed almost entirely during Chron 29r or Chron 31r.

We take advantage of a new compilation of Indian, French and other magnetic data, of improved satellite gravity anomaly, and of new seismic data which have recently appeared in the literature (Collier et al., 2004a, 2004b) to revisit the crustal nature, structure and age of the Gop Basin and its role in the geodynamical evolution of the Northwestern Indian Ocean.

\section{Geophysical signatures of the Gop Basin}

\subsection{Data}

The data used in the present study are sea-surface gravity and magnetic profiles acquired (1) by the National Institute of Oceanography, Goa, India, and (2) during French cruises Profindus 1 and 2 (also known as MD 51 and MD 58), complemented by (3) the GEODAS Marine Geology and Geophysics database (National Geophysical Data Centre, 1998). The study also used the satellite-derived gravity anomaly maps (Sandwell and 
Smith, 1997; 2003) and the recently acquired (Collier et al. 2004a, 2004b) multichannel seismic reflection section along profile $A B$ across the Gop Basin. The seismic refraction results have been obtained from OBS (Collier et al., 2004b) and sonobuoy (Naini and Talwani, 1982). The locations of gravity, magnetic, seismic reflection and refraction profiles used in the present study are shown in Fig. 2.

\subsection{Basement features from a seismic reflection section}

Fig. 3 shows the published seismic reflection section which extends from the Arabian Basin to the southern continental margin of Pakistan. The section clearly shows the presence of a $\sim 80 \mathrm{~km}$ wide ( $\mathrm{km} 115$ to 35) sediment filled graben, the Gop Basin, surrounded by two relatively higher basement features. A basement high, $\sim 20 \mathrm{~km}$ wide and -1.5 sec (twt), is observed in the central part of this graben. It has been delineated and named the Palitana Ridge by Malod et al. (1997). The basement high located immediately south of the Gop Basin ( $k m 175$ to 115) is the Laxmi Ridge while the one to the north (beyond km 35) most likely represents the southern continental margin of Pakistan.

\subsection{Gravity anomalies}

The north-south gravity anomaly profiles across the northern Arabian Basin and the Gop Basin (Fig. 4) show the presence of a broad free-air gravity low between the Arabian Basin and the Gop Basin. This E-W trending gravity low is the continuation of the characteristic gravity low associated with the Laxmi Ridge. Northwards of this gravity low, an E-W trending gravity high parallels the adjacent E-W segment of the Laxmi Ridge and corresponds to the major part of the Gop Basin. A short wavelength gravity low is present atop the crestal part of the broad gravity high of the Gop Basin. Gravity profiles SG-08, SG07, SG-06, CD2087-07 and AB (Fig. 4) depict this characteristic gravity low, which can be confidently traced to $\sim 64^{\circ} 15^{\prime} \mathrm{E}$ westwards and $\sim 65^{\circ} 10^{\prime} \mathrm{E}$ eastwards. Its continuation could not be traced further eastwards. This gravity low is subtle and not easily depicted on the satellite gravity anomaly map (Fig. 4). The composite gravity anomaly profile and seismic section presented in Fig. 3 shows that the characteristic gravity low coincides with the basement high region of the Palitana Ridge. Occasionally, a small short wavelength gravity high is observed (profiles $A B$ and SG-06 in Fig. 4) within the characteristic gravity low, which may reflect the local signature of the basement high feature of the Palitana Ridge. 


\subsection{Magnetic anomalies}

To depict the magnetic signature of the Gop Basin, we presented the magnetic data as a magnetic anomaly map (Fig. 5) and as projected profiles along the N-S direction (Fig. 6a). The dense coverage of crisscrossing sea-surface magnetic profiles over the study area allowed the computation of a magnetic anomaly grid after cross over error analysis and adjustment of the tracks.

The magnetic anomaly map (Fig. 5) depicts various zones with different magnetic fabric in the Gop Basin and its immediate neighbourhood. The Laxmi Ridge, associated with much subdued anomalies, is flanked on the north and south by prominent magnetic anomalies. Immediately south of the Laxmi Ridge (area A), a linear medium amplitude negative anomaly may correspond to anomaly A28ny ( 62.5 Ma; Chaubey et al., 1998; Miles and Roest, 1993). The three prominent magnetic lineations further south correspond to anomalies A27n, A26n and A25n. North of the Laxmi Ridge, a prominent E-W positive anomaly is observed in the Gop Basin (area B), flanked by two strong negative anomalies. This positive anomaly roughly coincides with the Palitana Ridge. North of this set is a strong

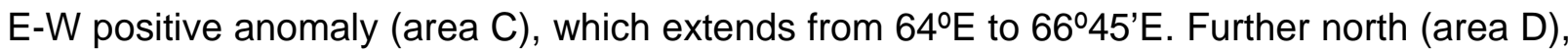
a weaker positive anomaly flanked by two negative anomalies exhibit a $\mathrm{N} 70^{\circ} \mathrm{E}$ trend. No distinct magnetic anomaly is observed between area D and the Pakistan shelf.

The prominent magnetic anomalies of the Gop Basin (Fig. 6a) display peak to peak amplitudes of $\sim 800 \mathrm{nT}$, stronger than any other anomalies in the area. They appear to be symmetrical about an axis which is somewhat shifted with respect to the apex of the Palitana Ridge. However, magnetic anomalies are usually not observed atop their causative bodies, because both the magnetization and the present day magnetic field are not vertical vectors. Given an elongated magnetized body, the anomaly observed along a crossing profile is skewed (or phase-shifted) by an angle which depends on the inclinations of the magnetization and present day magnetic field and the azimuth of the profile (e.g., Schouten and McCamy, 1972; Cande, 1976; Dyment et al., 1994). We therefore investigated the skewness of the Gop Basin magnetic anomalies by comparing two signals derived from these anomalies: the modulus of the analytic signal, a zero-phase signal (i.e. independent of the skewness factor) which reaches maxima at the top of magnetic contrasts (Nabighian, 1972, 1974) on one hand, and the observed anomalies gradually phase-shifted at regular angle intervals. The phase shift value for which the location of the inflection points on the 
phase-shifted anomaly profile and the maxima of the analytic signal modulus are coincident is the optimal skewness factor for this anomaly profile (Roest et al., 1992). The skewness factor determined over the 14 profiles considered in this study varies from 120 to 160 degrees, and gives an average value of 150 degrees which was used as the optimal skewness factor for the study area. Such a value, which corresponds almost to an inversion of the profile, is not surprising for E-W trending anomalies observed near the magnetic Equator. The anomaly profiles crossing the Gop Basin were deskewed with this factor and are presented in Fig. 6b, aligned with respect to the characteristic gravity low (marked by a red dash-dotted line) where observed.

From Fig. 6b, it is clear that the prominent negative deskewed magnetic anomaly coincides with the axis of the Palitana Ridge. So not only is the Palitana Ridge associated with a characteristic gravity low (atop a broad gravity high) but it is also associated with a prominent magnetic anomaly. Although the gravity low cannot be traced beyond $65^{\circ} 10^{\prime} \mathrm{E}$ eastwards (Fig. 4), the corresponding magnetic anomaly and its flanking positive anomalies are confidently traced eastwards up to $\sim 66^{\circ} \mathrm{E}$ (Fig. 5) and westwards, they are easily traced up to $\sim 63^{\circ} 45^{\prime} \mathrm{E}$, and possibly beyond with a slight NW trend. This set of E-W trending magnetic lineations therefore extends linearly over about 200 km in the Gop Basin (Fig. 5).

\section{Interpretation and discussion}

In order to decipher the nature, structure, and age of the Gop Basin and nearby features, we applied forward modelling to the gravity and magnetic anomalies, using additional constraints from published seismic reflection and refraction results. Potential field modelling is intrinsically non-unique, so such additional data are essential to narrow the range of possible solutions. In a first step, we obtained a reasonable crustal configuration based on gravity modelling. Subsequently, we used this configuration to model the magnetic anomalies, tried to identify the observed sequence of anomalies, and made inferences on the age of the Gop Basin.

\subsection{Interpretation of gravity anomalies in the Gop Basin.}

To investigate the crustal structure and density distribution of the Gop Basin and adjoining regions, we used a $\sim 500 \mathrm{~km}$-long satellite-derived gravity anomalies profile (GABH in Fig. 2) which extends from the Arabian Basin to the continental margin of 
Pakistan. We selected profile GABH because (1) it is orthogonal to the observed magnetic lineations, (2) a published multichannel seismic reflection section of recent vintage is available over segment AB (Collier et al., 2004a, 2004b), and (3) published (Collier et al., 2004b) refraction results are available along the nearby parallel profile RS (Fig. 2).

We constructed an initial crustal model by using the seismic reflection and refraction results of Collier et al., (2004a, 2004b). The shallower part (down to the basement) was constrained by the seismic reflection results, the deeper parts by the seismic refraction results. We used an average velocity of $2.73 \mathrm{~km} / \mathrm{s}$ for the sediments to convert the depth to basement from time to depth units throughout the profile. This value was assumed following the empirical formula provided by Malod et al. (1997) for the Gop Basin and the sediment velocities provided by Naini and Talwani (1982) for the Arabian Basin. As the velocity information from the recent data of Collier et al. (2004a, 2004b) is not available in digital form, we had to rely on the velocities of Naini and Talwani (1982) from stations close to the gravity profile (Fig. 2). The layer densities have been estimated based on the velocitydensity relationship of Ludwig et al. (1970). The bathymetry and basement reflection are available from seismic reflection data (Collier et al., 2004a, 2004b) only for segment $A B$ (Fig. 2). Along segments $\mathrm{GA}$ and $\mathrm{BH}$ the bathymetry has been obtained from the so-called "predicted bathymetry" derived from satellite altimetry (Smith and Sandwell, 1997) and the top of the basement has been assumed to coincide with the $5 \mathrm{~km} / \mathrm{s}$ velocity threshold observed on the OBS results (Collier et al., 2004b). As seen from Fig. 2, the gravity profile cuts across four geological domains - the Arabian Basin, the Laxmi Ridge, the Gop Basin and the southern continental margin of Pakistan. The lateral boundaries of each geological domain have been assumed from the structures revealed by the seismic reflection profile (Collier et al., 2004a, 2004b) and the shape of the gravity anomalies.

The initial crustal model was refined so as to obtain a reasonable good fit between the observed and computed anomalies. While refining the model, more reliable constraints such as the bathymetry, the depth to basement and the layer densities, have been kept unchanged, while the boundaries of the deeper crustal layers have been adjusted.

The final crustal model (Fig. 7) supports the presence of a $\sim 6 \mathrm{~km}$ thick oceanic crust in the Arabian Basin ( $\mathrm{km} 0$ to 170). Below the sediments (density $2.17 \mathrm{~g} / \mathrm{cm}^{3}$ ), the crust displays a two-layered structure made of Layers 2 and 3 (density $2.63 \mathrm{~g} / \mathrm{cm}^{3}$ and 2.88 
$\mathrm{g} / \mathrm{cm}^{3}$, respectively). On the continental shelf off Pakistan ( $\mathrm{km} 310$ to 500), the crustal model is consistent with a $\sim 14 \mathrm{~km}$ thick continental crust, which thickens landward. Although the densities assumed for the upper and lower layers are consistent with those of the upper and lower continental crust, this crust is much thinner than the adjacent continental crust of the Indian mainland ( $-35 \mathrm{~km}$, Kaila and Sain, 1997).

The part of the Laxmi Ridge cut across by the profile ( $\mathrm{km} 170$ to 230) consists of a $2.5 \mathrm{~km}$-thick layer of sediments overlying two crustal layers with densities $2.64 \mathrm{~g} / \mathrm{cm}^{3}$ and $2.86 \mathrm{~g} / \mathrm{cm}^{3}$ for the upper and lower layers, respectively. Again these densities are consistent with those of the upper and lower continental crust. The Laxmi Ridge appears to be isostatically balanced by a deeper Moho, resulting in a total crustal thickness of $11 \mathrm{~km}$. Our modelling therefore supports that the Laxmi Ridge is a region of thinned continental crust, in agreement with earlier works (Naini and Talwani, 1982; Talwani and Reif, 1998; Collier et al., 2004a, 2004b, 2008; Krishna et al., 2006; Bulychev et al., 2006).

The Gop Basin (km 230 to 310) is modelled with a $\sim 6 \mathrm{~km}$-thick two-layered crust (densities $2.66 \mathrm{~g} / \mathrm{cm}^{3}$ and $2.89 \mathrm{~g} / \mathrm{cm}^{3}$ for the upper and lower layers), which underlies a $-3.5 \mathrm{~km}$-thick layer of sediments. The gravity signature of the Palitana Ridge requires this structure to be compensated by a locally deeper ( $16 \mathrm{~km})$ Moho. Furthermore, a better fit with the observed gravity anomaly is achieved by adding locally, below the Palitana Ridge, a slightly lighter body (density $2.6 \mathrm{~g} / \mathrm{cm}^{3}$ ) beneath the upper crust (density $2.66 \mathrm{~g} / \mathrm{cm}^{3}$ ). The crustal thickness and densities of the Gop Basin are comparable to those of normal oceanic crust, the upper and lower crustal layers (density 2.66 and $2.89 \mathrm{~g} / \mathrm{cm}^{3}$ ) being Layers 2 and 3 of the oceanic crust, respectively. If the Palitana Ridge is an extinct spreading centre, the low-density body inferred under the fossil axis would resemble similar bodies postulated by Jonas et al. (1991). Free-air short wavelength gravity anomaly lows atop broader gravity highs appear to be the general signature of extinct spreading centres as, for example, in the Coral Sea (Weissel and Watts, 1979), in the Laxmi Basin (Bhattacharya et al., 1994a). Other fossil spreading centres in the Labrador Sea, Mascarene Basin, Tasman Sea, Western Philippine Basin, Parece Vela Basin, and on the Mathematician and Galapagos fossil spreading centres show a similar signature, as indicated by the gravity anomaly map derived from satellite altimetry (Sandwell and Smith, 1997, 2003). 


\subsection{Interpretation of magnetic anomalies in the Gop Basin}

As mentioned earlier, the Gop Basin exhibits a prominent linear positive magnetic anomaly flanked by symmetrical linear negative anomalies (area B in Fig. 5). Although such anomalies can be generated by a variety of magnetized sources, we interpret these anomalies as reflecting a two-limbed oceanic basin formed by seafloor spreading at the now extinct Palitana Ridge spreading centre, because (1) the anomalies show amplitudes comparable to the well established seafloor spreading anomalies of the nearby Arabian Basin; (2) they exhibit a remarkable coherency and continuity over $200 \mathrm{~km}$; (3) the central anomaly coincides with the Palitana Ridge, a prominent axial basement high, and the associated axial gravity low characteristic of other fossil spreading centres; (4) the deskewed magnetic anomalies show a clear symmetry with respect to the Palitana Ridge over the Gop Basin, delineated by a broad gravity high; (5) the crustal structure of the Gop Basin is compatible with oceanic crust. In the following sections, we try to identify the polarity sequence(s) that properly fit the observed anomalies assuming reasonable spreading rates and spreading rate variations.

For the magnetic modelling, we assume the spreading centre to coincide with the apex of the Palitana Ridge, and the outer limits of the magnetized layer to correspond to the limits of the Gop Basin as defined by a basement scarp observed in the seismic reflection data (Fig. 3). The synthetic magnetic anomalies are computed for E-W striking juxtaposed normally and reversely magnetized blocks. As we compare the modelled anomalies to deskewed anomalies, we compute the model to the pole.

The anomaly sequence in the Gop Basin is short, hence its identification by comparison with the geomagnetic polarity time scale is ambiguous at least. Additional time constraints come from the adjacent Arabian Basin, where the seafloor spreading history is well established (e.g., Chaubey et al., 1998, 2002; Dyment, 1998; Royer et al., 2002). These studies have identified a probable A28ny lineation ( $62.5 \mathrm{Ma})$ immediately south of Laxmi Ridge and A27n lineations ( $61.3 \mathrm{Ma})$ further south, and the entire sequence of conjugate magnetic anomalies from $A 27 n$ to the present are observed in the conjugate Arabian and Eastern Somali basins, between the Laxmi Ridge and the Seychelles Bank. If there was a seafloor spreading episode in the region landward of the Laxmi Ridge, such an episode reasonably predates the opening of the Carlsberg Ridge, which started at the time 
of anomaly A28n (or A27n) and may have been fully achieved only at the time of anomaly A24r ( $-55 \mathrm{Ma})$, as anomalies $A 25 n$ to $A 27 n$ are not observed in the eastern part of the Arabian and Eastern Somali basins. We therefore assume this period as the younger age bound in our attempt to identify the Gop Basin magnetic anomalies.

As a starting point we considered a simple model in which a central reversely magnetized block is flanked on both sides by normally magnetized blocks. Such a model may represent an axial anomaly A28r flanked by A29n, ( 63.6 - 64.7 Ma) or an axial anomaly A27r flanked by A28n ( 61.3 - 63.6 Ma). The anomalies computed from such a configuration do not match well with the shape of the observed anomalies, particularly conjugate second-order anomalies systematically observed on the flanks of the central anomaly (Fig. 6 and 8a). Such second-order anomalies can be simulated by adding a narrow reverse block within the flanking normally magnetized blocks. This observation indicates that the Gop Basin magnetic anomalies may reflect a longer history including at least three polarity reversals. Indeed, at slow spreading rates the observed magnetic anomalies often correspond to the combined effect of several blocks of different polarity (the "sequence effect" of Dyment et al., 1994), so the Gop Basin magnetic anomalies may also be caused by multiple blocks of normal and reverse polarities.

Based on the geomagnetic polarity time scale, we tried to find sequences of normally and reversely magnetized blocks and adjusted the width of the blocks to obtain a reasonable fit of the modelled anomalies with the deskewed ones. We rejected models which required wide and random variations of the spreading rate for almost each individual block. After many trials, we obtained two models which provide a fair match between the observed and computed anomalies with reasonable variations of the spreading rate. These two models correspond to: (1) anomaly sequence A31r- A25r ( 69.3 - 56.4 Ma, model A in Fig. 8a) and (2) anomaly sequence A29r-A25r ( 64.8 - 56.4 Ma, model B in Fig. 8a). Although A31r polarity interval spans a long period $(71.1-68.7 \mathrm{Ma})$, the first model only requires the younger part of this interval $(\sim 69.3-68.7 \mathrm{Ma})$ to be present in the Gop Basin. Similarly for the second model, only the younger part of anomaly A29r ( $64.8-64.7 \mathrm{Ma})$ may be present in the Gop Basin. In both models, the time of spreading extinction, A25r $(\sim 56.4 \mathrm{Ma})$, is not well constrained but has been adopted because it yields to a very slow spreading rate for the waning stage of the (soon to be extinct) spreading centre. 
We did not extend the interpretation of seafloor spreading magnetic anomalies beyond the Gop Basin anomalies as delineated above. The strong positive anomaly of area C (Fig. 5), although parallel to the Gop Basin anomalies, (1) does not exhibit a conjugate near Laxmi Ridge; (2) does not show the same consistency and continuity on the east of the area, and (3) is located beyond the scarp that may limit the oceanic extension of the Gop Basin (Fig. 3). The $\mathrm{N} 70^{\circ} \mathrm{E}$ trending anomalies of the area $\mathrm{D}$, where a central positive anomaly is flanked by two negative ones, could also have formed at an extinct spreading centre. However, their amplitudes are much lower, their consistency and continuity is quite poor and no basement high or short wavelength gravity low, characteristic of fossil spreading centres, are observed in association with the axial anomaly.

\subsection{Geodynamic consequences}

We have interpreted the sequence of magnetic anomalies observed in the Gop Basin either as anomalies A31r-A25r (i.e. $~ 69.3$ - $56.4 \mathrm{Ma}$, model A) or anomalies A29rA25r (i.e. $\sim 64.8$ - 56.4 Ma, model B). These two models have different implications for the regional geodynamic evolution. Model A considers a spreading regime for a period of about $13 \mathrm{~m} . \mathrm{y}$. and a half spreading rate that does not exceed $0.6 \mathrm{~cm} / \mathrm{yr}$, Model $\mathrm{B}$ a shorter duration of about 8.5 m.y. and a relatively faster half spreading rate reaching $3 \mathrm{~cm} / \mathrm{yr}$ (Fig. 8b). A more important difference is the relative timing of the spreading period with respect to the nearby emplacement of the Deccan Traps at $\sim 65$ Ma (e.g., Courtillot et al., 1986), a major volcanic event caused by the inception of the Reunion plume on the Indian lithosphere. As the Gop Basin is located less than $1000 \mathrm{~km}$ away from the centre of the Deccan Traps area, such a question is of importance to understand the geodynamic evolution of the Gop Basin in relation to the Reunion plume inception - whether rifting and spreading predated this event or they were one of its consequences.

Model A implies the existence of an active (although very slow) spreading centre in this region about 4 m.y. before the emplacement of the Deccan Trap and a significant decrease of the spreading rate around this event. This model suggests that the Deccan volcanism has post-dated the rifting and initiation of spreading by several million years and therefore both these events are probably unrelated. Conversely, Model B considers that seafloor spreading started at the time of the Deccan Trap emplacement and gradually slowed down until extinction. This model suggests that the plume inception is the cause of both the Deccan volcanism and the rifting and spreading in the Gop Basin. Both models 
consider that spreading along a new spreading centre, the paleo-Carlsberg Ridge separating Seychelles and Laxmi Ridge, initiated while the spreading centre in the Gop Basin was in its waning stage.

For both models, the spreading rate started to decrease at the time of the inception of the Reunion hotspot on the Indian lithosphere and the formation of the Deccan Trap. At first it may appear inconsistent that seafloor spreading slowed down and finally ceased whereas abundant magmatism was creating a large igneous province less than $1000 \mathrm{~km}$ away. However, it should be noted that the oceanic crust of the Gop Basin does not exhibit the classical rough topography associated to faults and tectonic extension of the ultraslow (Model A) or slow (Model B) spreading centres (e.g. Macdonald, 1982), but a smooth topography more typical of the hot and magmatic spreading centres (e.g. Canales et al., 1997), as shown by the seismic data of Collier et al. (2004a, 2004b) (Fig. 3b). Despite a decreasing spreading rate, the Gop Basin spreading centre kept such a smooth topography until its extinction, supporting that a strong magmatic activity persisted until spreading cessation and possibly beyond. The $\sim 2 \mathrm{~km}$ high (with respect to the nearby basement depth), $\sim 20 \mathrm{~km}$ wide Palitana Ridge is probably a construction associated with later stages of the volcanic activity, quite similar to the Hellas seamount on the Wharton fossil spreading centre (Hebert et al., 1999) and the Guadalupe Island on the Guadalupe fossil spreading centre (Batiza, 1977). The three major seamounts atop the inferred fossil spreading centre (the Panikkar Ridge) in the nearby Laxmi Basin (Bhattacharya et al., 1994a, 1994b), is another possible example of such strong magmatism at fossil ridges. This abundant magmatism in both the Gop and Laxmi basins most likely reflects a relationship with the nearby Reunion hotspot. Interestingly, spreading cessation at these fossil ridges did obviously not result from magma starvation but may reflect an incompatible geometry with respect to a changing geodynamic context. It is worth noting that the formation of the Palitana Ridge by later stages of volcanism on the dying Gop Basin spreading axis is not inconsistent with our simplified magnetic model of juxtaposed normal and reversed polarity blocks (Fig. 8). If the Palitana Ridge was formed during the period of dominantly reversed geomagnetic polarity spanning anomalies 28ny and 24no (62.5 - $55 \mathrm{Ma}$ ), any complex distribution of volcanics emplaced at slow rate should have the effect of a reversely magnetized block at the sea surface. 
The decrease of spreading rate and the extinction of the Gop Basin spreading centre is probably linked with the opening of the paleo-Carlsberg Ridge, another spreading centre located further south which propagated eastward and replaced the Gop Basin spreading centre as the plate boundary between Africa and India. Such an evolution has been described north of Iceland, with a new spreading centre, the Kolbeinsey Ridge, rapidly growing at the expense of the Aegir Ridge, resulting in the abandonment of latter and the isolation of a small continental sliver, the Jan Mayen micro-continent (e.g. Jung and Vogt, 1997). The comparison is adequate, indeed, as both cases involve slow spreading centres in the vicinity of a major hotspot. The locations and orientations of the spreading centres in the Gop and Laxmi basins were most likely inherited from a past three plate scenario for the separation of Laxmi Ridge from Indian mainland (Malod et al., 1997; Yatheesh, 2007), with the Laxmi Basin fossil spreading centre trending NW-SE, the Gop Basin fossil spreading centre trending E-W, and the inferred aulacogen of the Narmada rift graben (Fig. 1) forming the third arm of the triple junction, akin to the present day scenario of the Afar region. This geometry may not have been able to accommodate the divergence of the Indian and African plates in an area affected by the (apparent) southward migration of the Reunion hotspot. Therefore the paleo-Carlsberg Ridge developed in a location and orientation which could accommodate that situation better.

\section{Summary and conclusions}

Available magnetic data indicate that the Gop Basin region contains alternate bands of positive and negative magnetic anomalies with amplitudes comparable to the nearby seafloor spreading anomalies of the Arabian Basin. These magnetic lineations are fairly linear for long distance and are contiguous and parallel to the adjacent segment of the Laxmi Ridge. The Gop Basin region is also characterized by the presence of a characteristic short wavelength gravity low atop the crestal part of a broad wavelength gravity high. This gravity low coincides with the Palitana Ridge, a conspicuous basement high observed all along the axial part of the Gop Basin. Forward modelling of magnetic and gravity data, under the constrains of previous seismic results, suggest that: the crustal structure of the Gop Basin is consistent with oceanic crust and the magnetic lineations of the Gop Basin can be explained in terms of juxtaposed normally and reversely magnetized blocks within the uppermost basement layer. The sequence of these magnetized blocks is symmetrical about a central narrow reversely magnetized block, the axis of symmetry coinciding with the characteristic gravity anomaly and the prominent subsurface basement 
high trend of the Palitana Ridge. These observations supports the interpretation that the Gop Basin region is underlain by oceanic crust which was formed by an episode of a now extinct seafloor spreading and the Palitana Ridge is the extinct spreading centre related to that spreading.

With the available type of data, the anomaly sequence of the Gop Basin cannot be uniquely identified, and can be reasonably explained either as a A31r-A25r or as a A29rA25r sequence. Based on our model, the seafloor spreading in the Gop Basin would have started around $69 \mathrm{Ma}$ (A31r-A25r sequence) or around $65 \mathrm{Ma}$ (A29r-A25r sequence) and ceased around $56 \mathrm{Ma}$. Between 63 and $56 \mathrm{Ma}$ (A28n-A25), both the Gop Basin spreading centre and the Paleo-Carlsberg Ridge (which later created the Arabian and Eastern Somali basins between Seychelles and the Laxmi Ridge) were simultaneously active, before the latter took over. The spreading rates estimated under the assumptions of both these models suggest a significant slowing of spreading around $65 \mathrm{Ma}$, when the Reunion plume was forming the Deccan Traps on the adjacent western Indian mainland. After anomaly 28ny (63 Ma), the Gop Basin spreading centre was gradually waning whereas a new spreading centre, the paleo-Carlsberg Ridge, was developing further south, between the continental Laxmi Ridge and Seychelles block, close to the (relatively) southward migrating plume. Such a southward ridge jump is not observed in the later evolution of the paleoCarlsberg ridge. Instead, for more than 14 m.y. (Chrons 28ny - 22ny), the ridge accompanied the relative southward migration of the Reunion plume and relocated in the vicinity of the hotspot through ridge propagation and transferral of crust from one plate to other (Dyment, 1998; Chaubey et al., 2002; Royer et al., 2002). Widely observed highly reliable imprints of large scale ridge propagation in the area (Miles and Roest, 1993; Chaubey et al., 1998, 2002; Dyment, 1998; Miles et al., 1998; Royer et al., 2002) indeed strengthen this inference.

Evidence of extinct spreading in the Gop Basin has important consequences in the geodynamic evolution of the Arabian Sea and on the thermal history of the adjacent continental margins. It is therefore essential to precisely identify (i. e. date) the magnetic lineations of the Gop Basin. The experience of the present study shows that sea surface magnetic data is unable to provide the high resolution required to identify unambiguously the anomalies on such short anomaly sequences. Based on available technology, only a deep tow magnetic survey can provide the sufficiently high resolution magnetic data. Till 
such a deep tow magnetic survey is carried out in the Gop Basin (and the Laxmi Basin as well), time constraints in the early geodynamic evolutionary history of the Arabian Sea will remain a matter of speculation.

\section{Acknowledgements}

The authors are grateful to Dr. S.R. Shetye, Director, National Institute of Oceanography (Council of Scientific and Industrial Research), Goa for permission to publish this work. Parts of this work have been carried out by $\mathrm{VY}$ during his tenure at NCAOR, India, and his Post-doc tenure at IPGP, France. The financial support of the IndoFrench Centre for the Promotion of Advanced Research (IFCPAR) through Project 3307-1 is kindly acknowledged (Post-doctoral fellowship to VY, visits to GCB and JD). We thank Dr. Ph. Patriat for useful discussions and Drs. J.S. Collier and Ch. Lane for providing the end coordinates of their seismic reflection profile in the Gop Basin. We are indebted to Dr. Steve Cande and an anonymous reviewer for their careful review of the manuscript and valuable comments. All figures were drafted with the GMT software (Wessel and Smith, 1995). This is NIO contribution no. 4537 and IPGP contribution no. 2505.

\section{References}

Batiza, R., 1977. Petrology and chemistry of Guadalupe Island: an alkali seamount on a fossil ridge crest. Geology 5, 760-764.

Bhattacharya, G.C., Chaubey, A.K., 2001. Western Indian Ocean - a glimpse of the tectonic scenario, in: Sengupta, R., Desa, E. (Eds.), The Indian Ocean - A Perspective. Oxford \& IBH Pub. Company Ltd., New Delhi, pp. 691-729.

Bhattacharya, G.C., Chaubey, A.K., Murty, G.P.S., Gopala Rao, D., Scherbakov, V.A., Lygin, V.A., Philipenko, A.I., Bogomyagkov, A.P., 1992. Marine magnetic anomalies in the northeastern Arabian Sea, in: Desai, B.N. (Ed.). Oceanography of the Indian Ocean, Oxford-IBH, New Delhi, pp. 503-509.

Bhattacharya, G.C., Chaubey, A.K., Murty, G.P.S., Srinivas, K., Sarma, K.V.L.N.S., Subrahmanyam, V., Krishna, K.S., 1994a. Evidence for seafloor spreading in the Laxmi Basin, northeastern Arabian Sea. Earth Planet. Sci. Lett. 125, 211-220.

Bhattacharya, G.C., Murty, G.P.S., Srinivas, K., Chaubey, A.K., Sudhakar, M., Nair, R.R., 1994b. Swath bathymetric investigation of the seamounts located in Laxmi Basin, Eastern Arabian Sea. Mar. Geodesy 17, 169-182. 
Bulychev, A.A., Gilod, D.A., Mazo, E.L., Schreider, A.A., 2006. Features of the crustal structure of the Arabian Sea. Oceanology 46 (3), 418-429.

Canales, J.P., Danobeitia, J.J., Detrick, R.S., Hooft, E.E.E., Bartolome, R., Naar, D.F., 1997. Variations in axial morphology along the Galapagos Spreading Centre and the influence of the Galapagos hotspot, J. Geophys. Res. 102, 27341-27354.

Cande, S.C., 1976. A paleomagnetic pole from Late Cretaceous marine magnetic anomalies in the Pacific. Geophys. J. R. Astron. Soc. 44, 547-566.

Cande, S.C., Kent, D.V., 1995. Revised calibration of the geomagnetic polarity time scale for the Late Cretaceous and Cenozoic. J. Geophys. Res. 100, 6093-6095.

Chaubey, A.K., Bhattacharya, G.C., Murty, G.P.S., Desa, M., 1993. Spreading history of the Arabian Sea: some new constraints. Mar. Geol. 112, 343-352.

Chaubey, A.K., Bhattacharya, G.C., Murty, G.P.S., Srinivas, K., Ramprasad, T., Rao, D.G., 1998. Early Tertiary seafloor spreading magnetic anomalies and paleo-propagators in the northern Arabian Sea. Earth Planet Sci. Lett. 154, 41-52.

Chaubey, A.K., Dyment, J., Bhattacharya, G.C., Royer, J.Y., Srinivas, K., Yatheesh, V., 2002. Paleogene magnetic isochrons and palaeo-propagators in the Arabian and Eastern Somali basins, NW Indian Ocean, in: Clift, P.D., Croon, D., Gaedicke, C., Craig, J. (Eds.), The Tectonic and Climatic Evolution of the Arabian Sea Region. Geological Society, London, Special Publications 195, pp. 71-85.

Collier, J.S., Minshull, T.A., Whitmarsh, R.B., Kendall, J.M., Lane, C.I., Sansom, V., Rumpker, G., Ryberg, T., 2004a. Geophysical investigation of a conjugate pair of rifted margins formed at high extension rate: Laxmi Ridge - Northern Seychelles Bank, Western Indian Ocean, in: InterMARGINS Workshop: "Modelling the extensional Deformation of the Lithosphere" (IMEDL), Pontresina (Swiss Alps), Poster and abstract pp. 30.

Collier, J.S., Minshull, T.A., Kendall, J.M., Whitmarsh, R.B., Rumpker, G., Joseph, P., Sampson, P., Lane, C.I., Sansom, V., Vermeesch, P.M., Hammond, J., Wookey, J., Teanby, N., Ryberg, T., Dean, S.M., 2004b. Rapid continental breakup and microcontinent formation in the Western Indian Ocean. EOS, Trans. Am. Geophys. Union 85, 481.

Collier, J.S., Sansom, V., Ishisuka, O., Taylor, R.N., Minshull, T.A., Whitmarsh, R.B., 2008. 
Age of Seychelles-India break-up. Earth Planet Sci. Lett. 272, 264-277.

Courtillot, V., Besse, J., Vandamme, D., Montigny, R., Jaeger, J.J., Capetta, H., 1986. Deccan flood basalts at the Cretaceous/ Tertiary boundary? Earth Planet. Sci. Lett. 80, 361-374.

Dyment, J., 1998. Evolution of the Carlsberg Ridge between 60 and $45 \mathrm{Ma}$ : ridge propagation, spreading asymmetry, and the Deccan-Reunion hotspot. J. Geophys. Res. 103, 24067-24084.

Dyment, J., Cande, S.C., Arkani-Hamed, J., 1994. Skewness of marine magnetic anomalies created between 85 and $40 \mathrm{Ma}$ in the Indian Ocean. J. Geophys. Res. 99 (B12), 121-124.

Hebert, H., Villemant, B., Deplus, C., Diament, M., 1999. Contrasting geophysical and geochemical signatures of a volcano at the axis of the Wharton fossil ridge (NE Indian Ocean), Geophys. Res. Lett. 26, 1053-1056.

Jonas, J., Hall, S., Casey, J. F., 1991. Gravity anomalies over extinct spreading centres: a test of gravity models of active centres. J. Geophys. Res. 96, 11759-11777.

Jung, W.Y., Vogt, P., 1997. A gravity and magnetic anomaly study of the extinct Aegir Ridge, Norwegian Sea, J. Geophys. Res. 102, 5065-5089.

Kaila, K.L., Sain, K., 1997. Variation of crustal velocity structure in India as determined from DSS studies and their implications on regional tectonics. J. Geol. Soc. India 49, 395407.

Krishna, K.S., Rao, D.G., Sar, D., 2006. Nature of the crust in the Laxmi Basin $\left(14^{\circ}-20^{\circ}\right)$, western continental margin of India. Tectonics 25 (TC1006), doi:10.1029/2004TC001747.

Ludwig, W.J., Nafe, J. E., Drake, C. L., 1970. Seismic refraction, in: Maxwell, A.E. (Ed.), The Sea, Wiley-Interscience, New York, pp. 53-84.

Macdonald, K.C., 1982. Mid-Ocean Ridges: Fine Scale Tectonic, Volcanic and Hydrothermal Processes within the Plate Boundary Zone, Ann. Rev. Earth Planet. Sci. $10,155-90$

Malod, J.A., Droz, L., Mustafa Kamal, B., Patriat, P., 1997. Early spreading and continental to oceanic basement transition beneath the Indus-deep sea fan: northeastern 
Arabian Sea. Mar. Geol. 141, 221-235.

Masson, D.G., 1984. Evolution of the Mascarene Basin, Western Indian Ocean and the significance of the Amirante arc. Mar. Geophys. Res. 6, 365-382.

McKenzie, D., Sclater, J.G., 1971. The evolution of the Indian Ocean since the Late Cretaceous. Geophys. J. R. Astron. Soc. 25, 437-528.

Mercuriev, S., Patriat, P., Sochevanova, N., 1996. Evolution de la dorsale de Carlsberg: evidence pour une phase d'expansion tres lente entre 40 et $25 \mathrm{Ma}$ (A18 a A7). Oceanol. Acta 19(1), 1-13.

Miles, P.R., Munschy, M., Segoufin, J., 1998. Structure and early evolution of the Arabian Sea and East Somali Basin. Geophys. J. Int. 15, 876-888.

Miles, P.R., Roest, W.R., 1993. Earliest seafloor spreading magnetic anomalies in the north Arabian Sea and the ocean-continent transition. Geophys. J. Int. 115, 1025-1031.

Minshull, T.A., Lane, C.I., Collier, J.S., Whitmarsh, R.B., 2008. The relationship between rifting and magmatism in the northeastern Arabian Sea. Nature Geosci. 1, 463-467.

Müller, R.D., Royer, J.Y., Lawver, L.A., 1993. Revised plate motions relative to the hotspot from combined Atlantic and Indian Ocean hotspot tracks. Geology, 21, 275-278.

Nabighian, M.N., 1972. The analytic signal of two-dimensional magnetic bodies with polygonal cross-section: Its properties and use for automated anomaly interpretation. Geophysics 37 (3), 507-517.

Nabighian, M.N., 1974. Additional comments on the analytic signal of two-dimensional magnetic bodies with polygonal cross section. Geophysics 39 (1), 85-92.

Naini, B.R., Talwani, M., 1982. Structural framework and the evolutionary history of the continental margin of Western India, in: Watkins, J.S., Drake, C.L. (Eds.), Studies in Continental Margin Geology, American Association of Petroleum Geologists, pp. 67191.

National Geophysical Data Centre, 1998. GEODAS CD-ROM, Worldwide Marine Geophysical Data, National Oceanic and Atmospheric Administration, US Department of Commerce, Washington, DC.

Norton, I.O., Sclater, J.G., 1979. A model for the evolution of the Indian Ocean and the break-up of Gondwanaland. J. Geophys. Res. 84 (B12), 6803-6830. 
Roest, W.R., Hamed, A., Verhoef, J., 1992. The seafloor spreading rate dependence of the anomalous skewness of marine magnetic anomalies. Geophys. J. Int. 109, 653-669.

Royer, J.Y., Chaubey, A.K., Dyment, J., Bhattacharya, G.C., Srinivas, K., Yatheesh, V., Ramprasad, T., 2002. Paleogene plate tectonic evolution of the Arabian and Eastern Somali basins. In: Clift, P.D., Croon, D., Gaedicke, C., Craig, J. (Eds.). The Tectonic and Climatic Evolution of the Arabian Sea Region. Geological Society, London, Special Publications 195, pp. 7-23.

Sandwell, D.T., Smith, W.H.F., 1997. Marine gravity anomaly from Geosat and ERS I satellite altimetry. J. Geophys. Res. 102, 10039-10054.

Sandwell, D.T., Smith, W.H.F., 2003. World Gravity Image version 11.2, 2 minute resolution, $72^{\circ} \mathrm{S}$ to $72^{\circ} \mathrm{N}$. ftp://topex.ucsd.edu/pub/global_grav_2min/.

Schlich, R., 1982. The Indian Ocean: aseismic ridges, spreading centres and basins. In: Nairn, A.E.M., Stehli, F.G. (Eds.). The Ocean Basins and Margins, Plenum Press 6, pp. 51-147.

Schouten, H., McCamy, K., 1972. Filtering marine magnetic anomalies. J. Geophys. Res. 77, 7089-7099.

Shreider, A.A., 1998. Ancient paleomagnetic anomalies of the Arabian Sea. Oceanology 38(6), 823-829.

Smith, W.H.F., Sandwell, D.T., 1997. Global Seafloor topography from satellite altimetry and ship depth soundings. Science 277, 1956-1962.

Talwani, M., Reif, C., 1998. Laxmi Ridge- a continental sliver in the Arabian Sea. Mar. Geophys. Res. 20, 259-271.

Weissel, J.K., Watts, A.B., 1979. Tectonic evolution of the Coral Sea Basin. J. Geophys. Res. 84 (B9), 4572-4582.

Wessel, P., Smith, W.H.F., 1995. New version of the Generic Mapping Tools released. EOS, Trans. Am. Geophys. Union 76, 329.

Yatheesh, V., 2007. A study of tectonic elements of the western continental margin of India and adjoining ocean basins to understand the early opening of the Arabian Sea. Ph.D. Thesis, Goa University, India. 


\section{Figure captions}

Fig. 1: General map of the continental margin and adjoining deep offshore region off western India / southern Pakistan along with selected bathymetric contours. The thick dashed line is the gravity low axis of the Laxmi Ridge and the thick continuous line is its bathymetric limit after Bhattacharya and Chaubey (2001). Darker shaded areas within India are the extents of Deccan Traps. Solid dots joined by thick black line correspond to the reconstructed track of the Reunion plume (after Muller et al. 1993) and the numbers beside the solid dots are the predicted ages in Ma. The dashed box indicates the outline of the study area. GB: Gop Basin; LB: Laxmi Basin; LAB: Laccadive Basin; MR: Murray Ridge; LR: Laxmi Ridge; LP: Laccadive Plateau; NR: Narmada Rift

Fig. 2: Locations of gravity, magnetic and seismic profiles used in the present study. Thin black lines represent sea-surface gravity and magnetic profiles. Thick dotted line $(A B)$ represents the seismic reflection profile presented in Fig. 3. Thin dashed line $(\mathrm{GABH})$ represent the gravity anomaly profile presented in Fig. 7. Locations of OBS refraction stations (of Collier et al., 2004a, 2004b) and locations of sonobuoy refraction stations (of Naini and Talwani, 1982) are marked by open triangles and solid stars (annotated with station numbers), respectively. Dark and light grey shaded areas mark the extent of the Laxmi Ridge (LR) and gravity high region, respectively, both approximated from free-air gravity anomaly contours derived from Satellite altimetry (Sandwell and Smith, 1997). Hatched area represents the extent of the Palitana Ridge (PTR) defined from basement contour map of Malod et al. (1997). The thick black lines and dashed lines in the Arabian Basin are the magnetic lineations and pseudofaults, respectively, as mapped by Chaubey et al. (2002).

Fig. 3: Gravity and magnetic signatures (top), seismic section (middle) and interpreted line drawing showing the seafloor and basement (bottom) along profile $A B$, which extends from the Arabian Basin to the 
continental margin of southern Pakistan and cut across the Laxmi Ridge, Gop Basin and the Palitana Ridge (modified after Collier et al., 2004b). Location of the profile is shown in Fig. 2. PTR: Palitana Ridge

Fig. 4: Free-air gravity anomaly map derived from satellite altimetry (Sandwell and Smith, 1997) in the Gop Basin and its neighbourhood. Also shown are selected along-track projected sea-surface gravity profiles with cruise identifiers. The SG lines represent profiles along which the gravity anomalies have been extracted from satellite derived gravity anomalies grid. Outlines of the Palitana (PTR) and Laxmi (LR) ridges are shown as thick dotted and dashed black lines, respectively. GB: Gop Basin.

Fig. 5: Magnetic anomaly map in the Gop Basin and its neighbourhood. Different zones discussed in the text have been labelled (A, B, C, D). Identified magnetic anomalies in the Arabian Basin have been labelled after Chaubey et al. (2002). Other details are as in Fig. 4.

Fig. 6: Selected magnetic profiles [(a) observed profiles and (b) deskewed profiles)] projected perpendicular to the strike of the inferred magnetic lineations and stacked with respect to the characteristic short wavelength gravity low (SWL) axis atop the broad gravity high of the Gop Basin (GB). Where axis of the gravity low could not be traced, the profiles are stacked based on contiguity of the prominent magnetic anomalies. Thick dash-dotted line is the axis of stacking of magnetic anomalies and it is in red colour wherever the axis of the SWL could be traced. Pink lines represent inter-profile correlation of anomalies; blue dotted lines represent northerly and southerly boundaries of the Laxmi Ridge (LR) region along the profile crossings. After deskewing, magnetic anomalies are located above their causative source and a positive magnetization contrast is associated to a positive anomaly. The grey-shaded zones represent zones of positive deskewed magnetic anomalies flanking the central prominent negative deskewed magnetic anomaly which coincides with the SWL / Palitana Ridge. Locations of the magnetic profiles are shown in Fig. 2.

Fig. 7: Gravity anomaly modelling along profile $\mathrm{GABH}$ from the Arabian Basin 
to the continental margin of southern Pakistan. Top: Observed (continuous lines) and computed (dotted lines) gravity anomalies. Bottom: Crustal structure with densities and crustal velocities (in the box). PTR: Palitana Ridge; LCC: Lower continental crust; UCC: Upper continental crust. The location of the profile is shown in Fig. 2.

Fig. 8: (a) Two possible interpretations of magnetic anomalies in the Gop Basin. Model A corresponds to anomaly sequence A25r-A31r and Model B to anomaly sequence A25r-A29r. Modelled magnetic anomalies computed to the pole are shown along with deskewed profile CD2087-06 (projected to an azimuth of $0^{\circ}$ ). This profile is located in the close vicinity of seismic profile $A B$, along which digital magnetic anomaly data were not available to us. Magnetized layer (with a magnetization of $20 \mathrm{~A} / \mathrm{m}$ ) is considered to be $0.5 \mathrm{~km}$ thick and upper surface is approximated to the basement topography derived from seismic reflection. Normally magnetized blocks are indicated with grey shading. The slow spreading rate results in a single observed magnetic anomaly corresponding to the combined effect of several polarity reversals. Modelled magnetized bodies are shown along with the inferred crustal structure of the Gop Basin to emphasize that the assumed magnetized bodies lie within the oceanic basement layer as derived from gravity modelling. Other details are as in Fig. 7.

(b) Half spreading rates yielded by the two models shown in (a). Dashed line corresponds to Model A (i. e. anomaly sequence A31rA25r) and continuous line corresponds to Model B (i.e. anomaly sequence A29r-A25r). Grey shaded limit corresponds to the timing of the maximum volcanic activity of the Reunion hotspot on the adjacent western Indian mainland. 


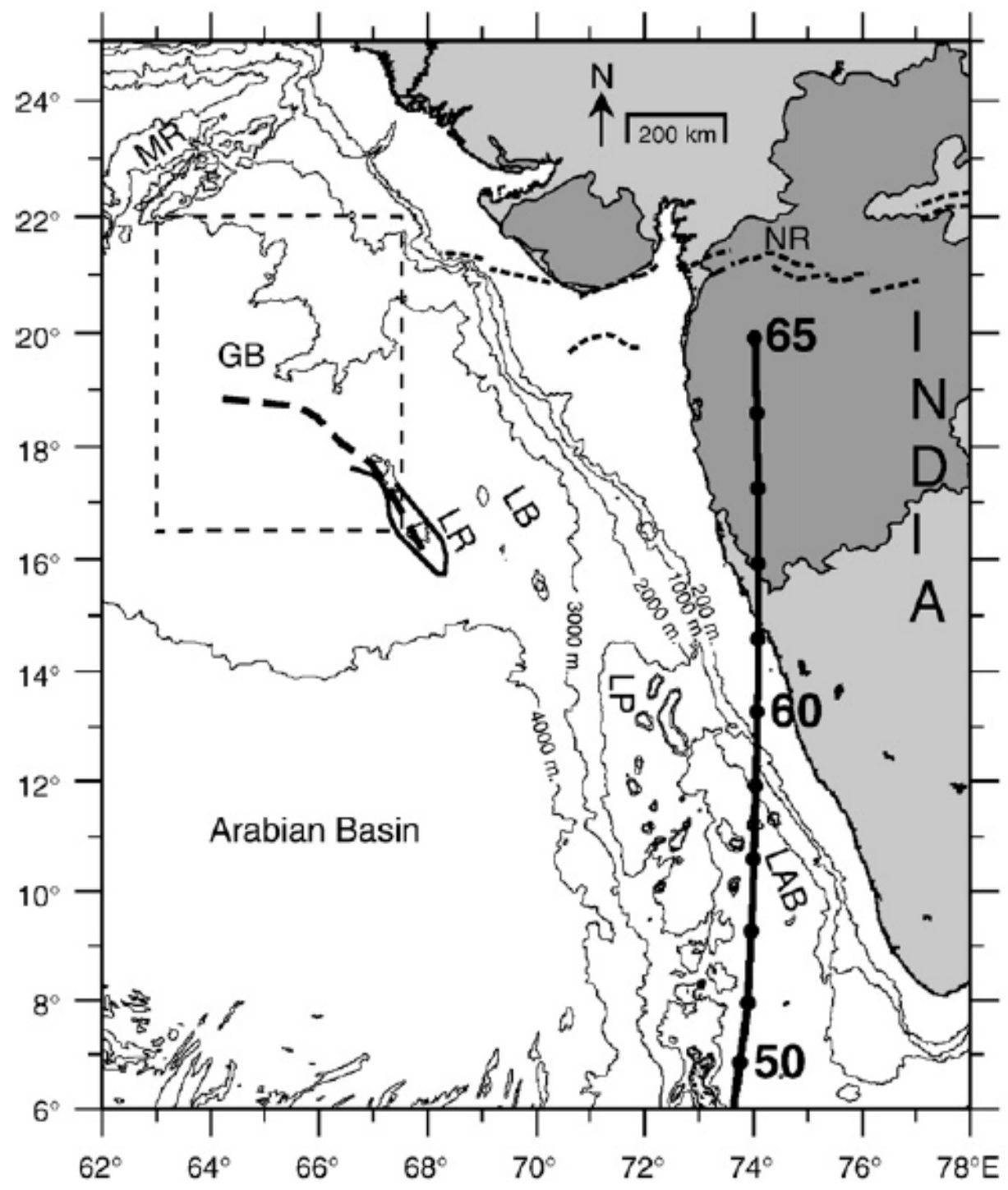

Fig. 1 


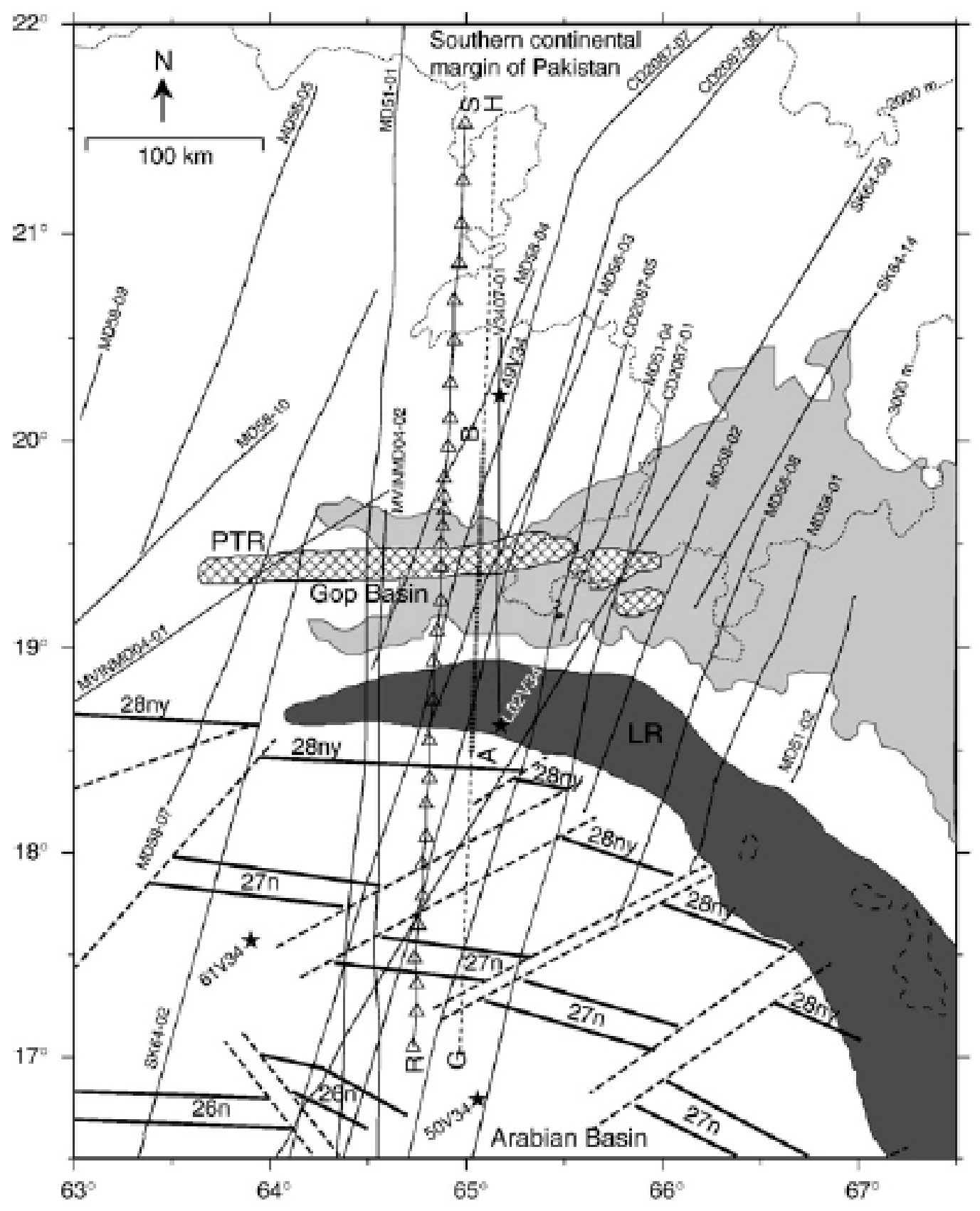

Fig. 2 

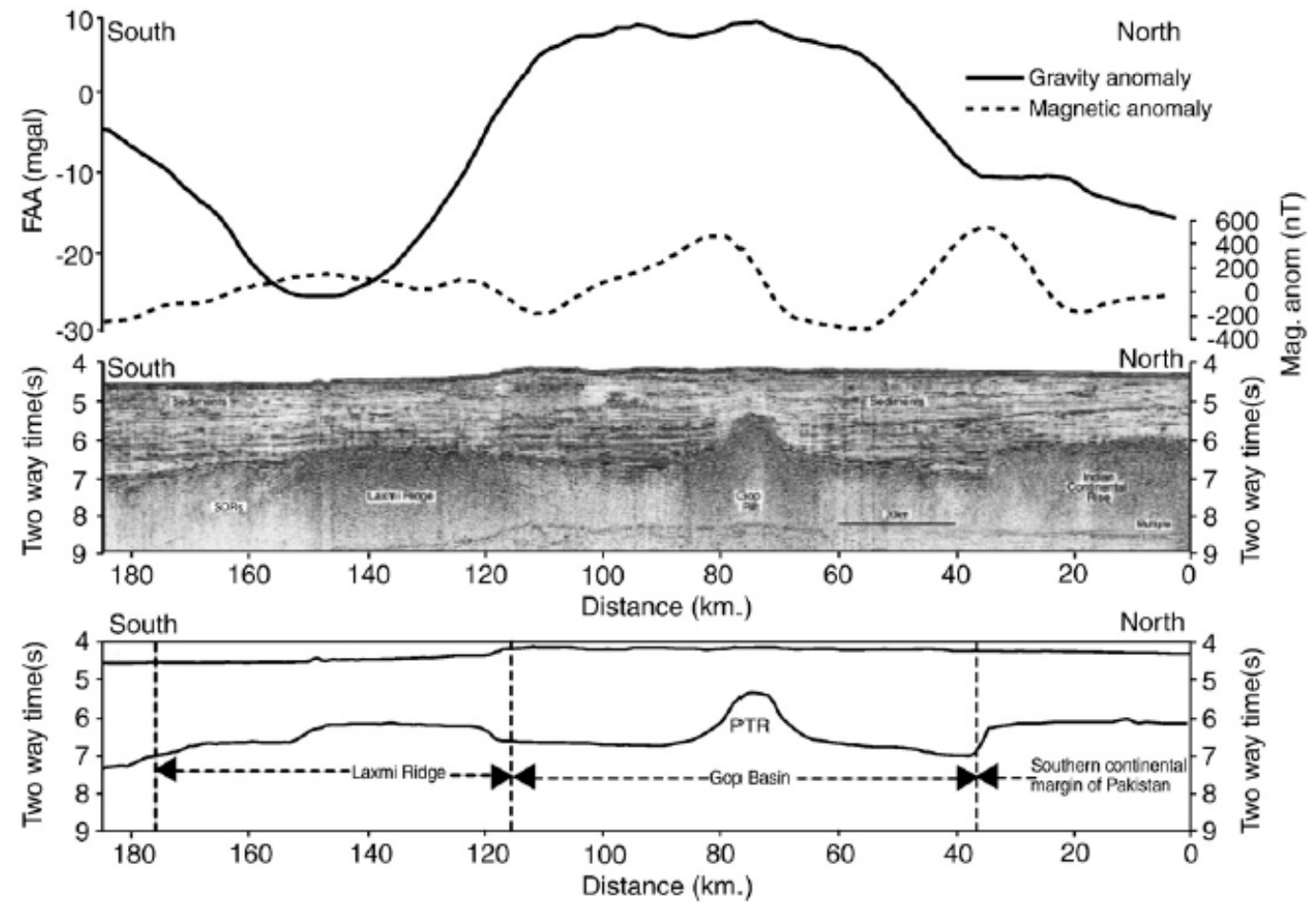

Fig. 3 


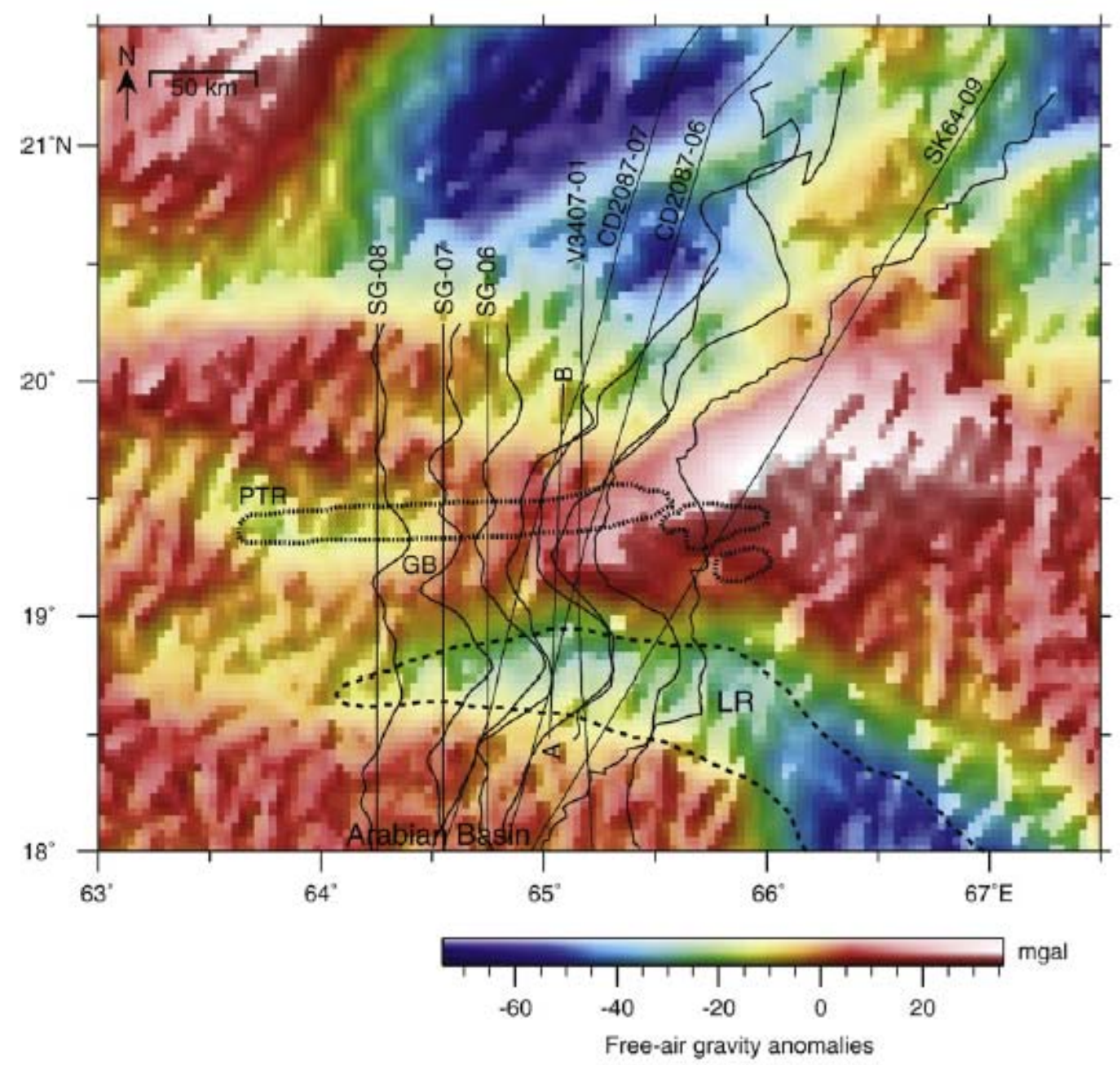

Fig. 4 

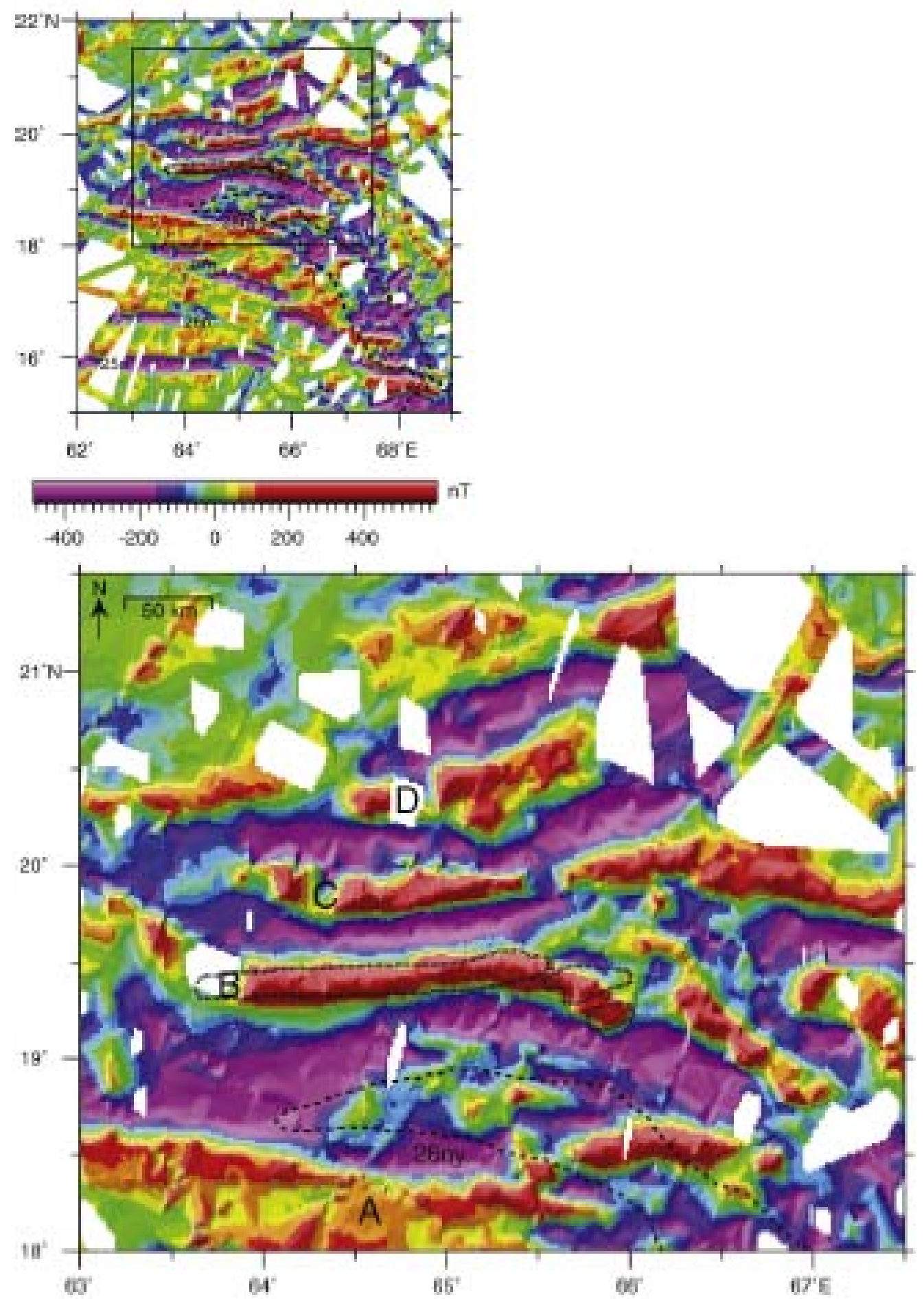

Fig. 5 


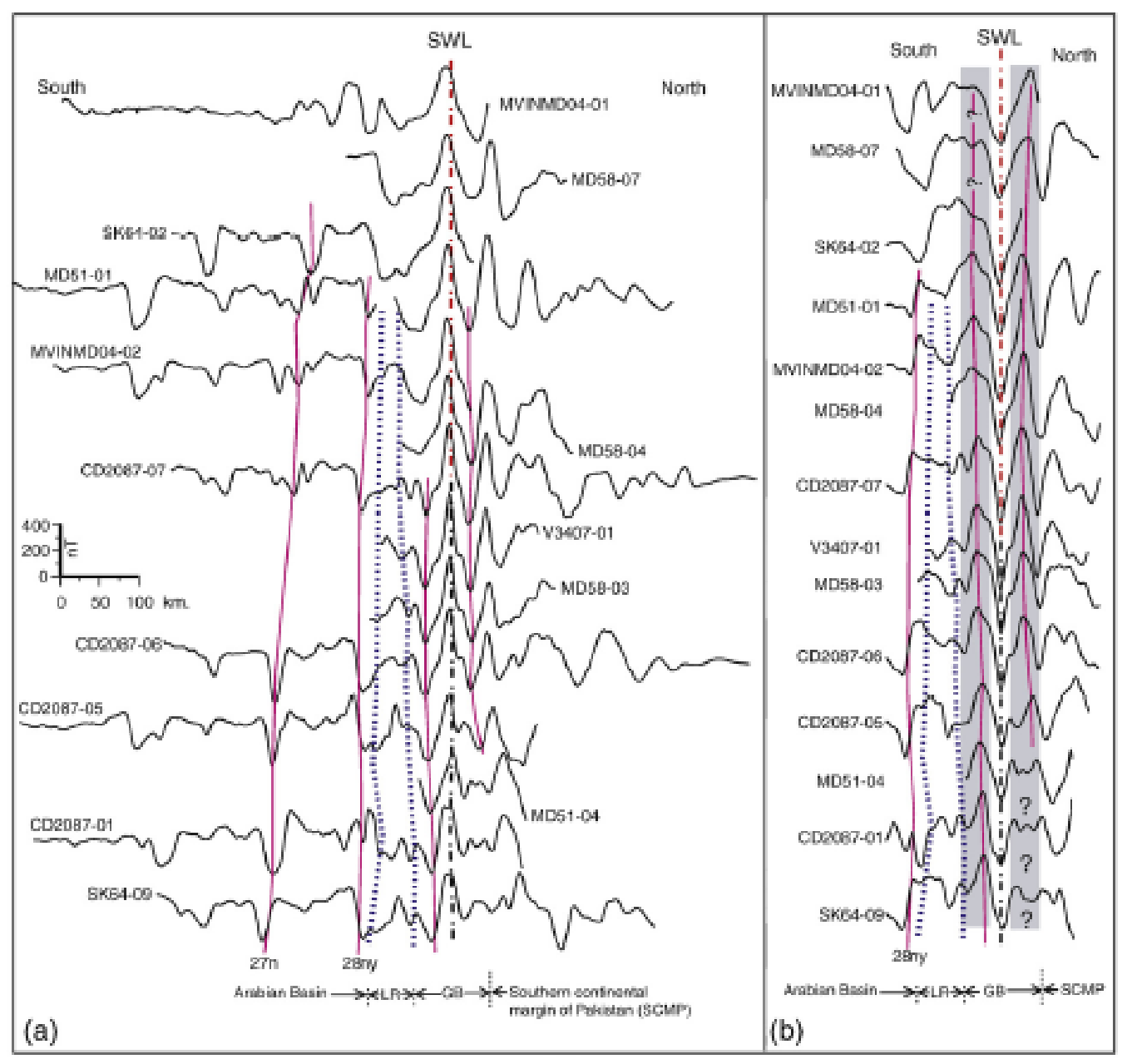

Fig. 6 

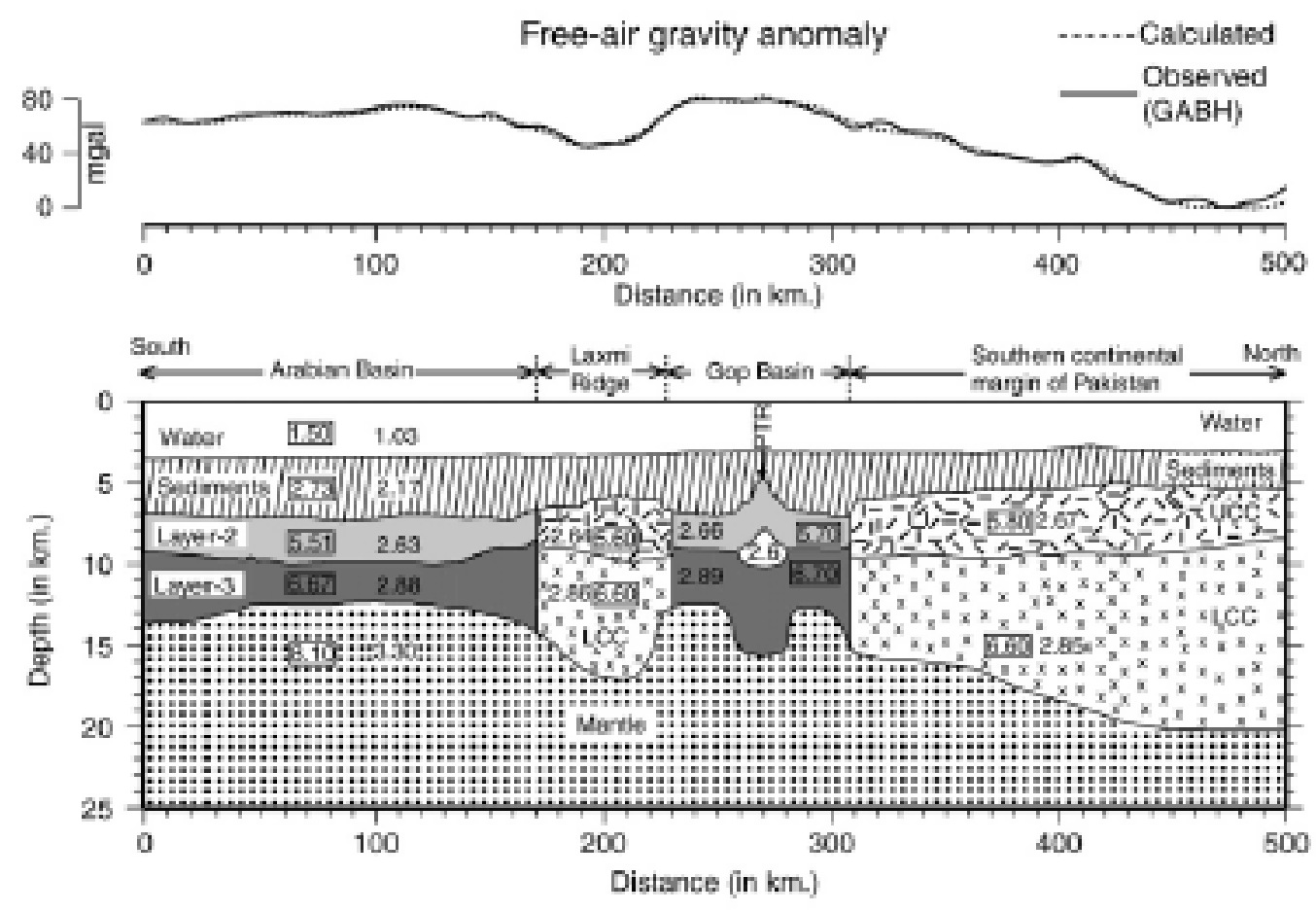

Fig. 7 

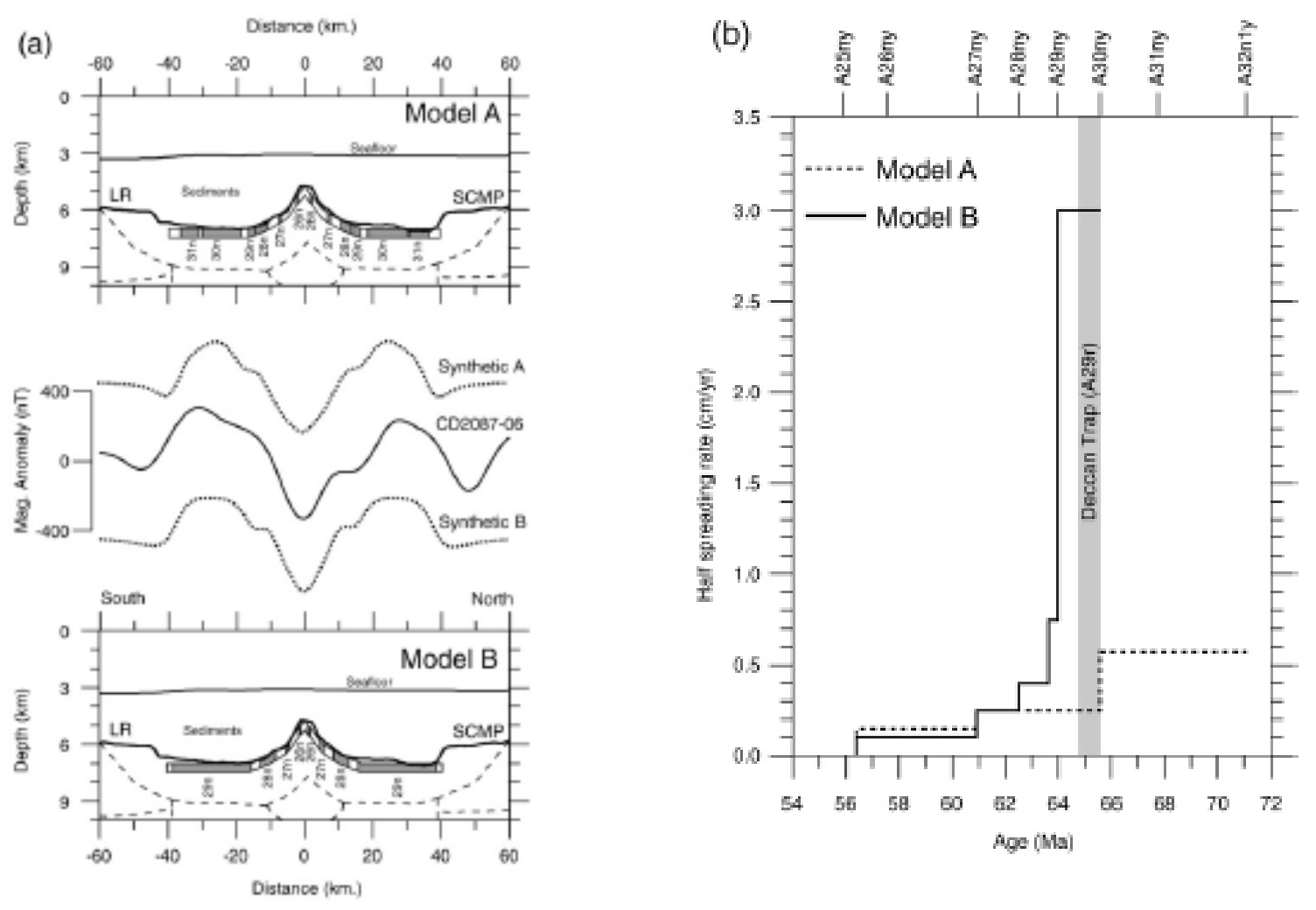

Fig. 8 